\title{
Hybridization between Townsend's Dendroica townsendi and black- throated green warblers $D$. virens in an avian suture zone
}

\author{
David P. L. Toews, Alan Brelsford and Darren E. Irwin \\ D. P. L. Toews (toews@zoology.ubc.ca), A. Brelsford and D. E. Irwin, Dept of Zoology, and Biodiversity Research Centre, Univ. of British \\ Columbia, 6270 Univ. Blvd., Vancouver, BC, V6T 1Z4, Canada
}

\begin{abstract}
Hybrid zones between species provide natural systems for the study of processes involved in divergence, reproductive isolation and speciation. Townsend's Dendroica townsendi and black-throated green D. virens warblers are phenotypically and genetically divergent groups that occur in western and eastern North America respectively, with potential for range contact in the Rocky Mountains of British Columbia, where other west-east avian pairs come into contact. Although one potential hybrid (a phenotypic Townsend's warbler with the black-throated green mitochondrial DNA) has been previously reported, there have been no studies of interactions between the taxa in potential areas of sympatry. To determine whether interbreeding between these species is a regular occurrence we examined variation in individuals across the area of putative range overlap. Analysis of plumage, morphology, and mitochondrial (COI) and nuclear molecular markers (CHD1Z and numt-Dco1) shows surprisingly extensive hybridization between these species, with at least 38\% of individuals in the hybrid zone being either hybrids or backcrosses. Each of the traits displays a sigmoidal cline centred along the eastern slope of the Rocky Mountains (molecular cline centres averaging $50 \mathrm{~km}$ east of the crest of the Rockies, ranging from 41 to $56 \mathrm{~km}$ ). The clines are narrow (average molecular cline width is $60 \mathrm{~km}$, ranging from 40 to $87 \mathrm{~km}$ ) relative to the dispersal distance of related warbler species, suggesting that selection is maintaining the hybrid zone; we discuss possible sources of selection. Given the narrowness of the zone we recommend the two forms should continue to be treated as separate taxonomic species. Townsend's warblers also form an extensively studied hybrid zone with their more closely related southern relative, the hermit warbler $D$. occidentalis. The combined system of three discrete forms separated by narrow hybrid zones provides an excellent system for the study of hybridization, reproductive isolation and speciation.
\end{abstract}

Determining the frequency with which diverging taxa interbreed in nature can reveal the extent to which they are reproductively isolated (Grant and Grant 1992). At least in birds, rare hybridization events have been noted between many pairs of species (Mayr and Short 1970). These uncommon events usually tell us little about the evolutionary history or taxonomic status of the taxa in question (although see Vallender et al. 2009). In contrast, extensive hybridization in hybrid zones can have a number of important taxonomic and conservation implications (Price 2008). Hybridization can be a source of evolutionary novelty, introducing potentially adaptive alleles to the gene pool of a species (Short 1972). Hybridization between domesticated dogs and grey wolves, for instance, is thought to have introduced a putatively advantageous coat colour allele from canines to their wild relatives, producing a dark colour morph, which has been maintained in natural grey wolf populations in North America (Anderson et al. 2009). In contrast, some cases of hybridization have led to the erosion of differences between species and the loss of unique evolutionary history upon secondary contact (Seehausen 2006). For example, the asymmetric introgres- sion of blue-winged warbler Vermivora cyanoptera alleles into golden-winged warblers $V$. chrysoptera has left only a few remaining populations that contain genetically pure golden-winged warblers (Vallender et al. 2007). In either scenario, studying the dynamics of hybridization between diverging taxa can lead to an understanding of the genes and traits important in the evolution of reproductive isolation (Payseur 2010).

Areas where numerous different pairs of related taxa come into secondary contact are termed 'suture zones' (Remington 1968, Swenson and Howard 2005). We have recently described a suture zone in northeastern British Columbia, Canada, that is home to a number of avian contact zones, some previously unknown to science. This is where the Pacific wren Troglodytes pacificus and the winter wren $T$. hiemalis overlap in their distribution (Toews and Irwin 2008), where Audubon's warblers Dendroica auduboni and myrtle warblers $D$. coronata hybridize (Hubbard 1969, Barrowclough 1980, Brelsford and Irwin 2009) and where a recently described hybrid zone between MacGillivray's warblers Oporonis tolmiei and mourning warblers O. philadelphia is located (Irwin et al. 2009). 
Another pair of closely related species that has been proposed to come into contact in this area (M. Phinney pers. comm.) are Townsend's warblers Dendroica townsendi, which mostly breed west of the Rocky Mountains, and black-throated green warblers D. virens, which generally breed east of the Rocky Mountains (Fig. 1). A hybrid zone between Townsend's warblers and their southern relatives, hermit warblers $D$. occidentalis, has been the subject of detailed study in Washington and Oregon (Rohwer and Wood 1998, Krosby and Rohwer 2009). This is a moving hybrid zone, with phenotypic Townsend's warblers moving south and replacing hermit warblers, leaving the genetic footprint of hermit warbler mitochondrial DNA in its wake (Krosby and Rohwer 2009). Mitochondrial DNA reveals that Townsend's and hermit warblers are sister to the group that contains black-throated green warblers and the endangered golden-cheeked warbler $D$. chrysoparia (Lovette et al. 2010) and the two pairs are estimated to have diverged from each other approximately one million years ago (Weir and Schluter 2004, Rabosky and Lovette 2008). Motivated by these interesting hybridization dynamics between Townsend's and hermit warblers, we wished to investigate whether Townsend's and black-throated green warblers might also hybridize if they come into contact.

Aside from their mostly geographically separate breeding distributions, Townsend's and black-throated green warblers differ in a number of phenotypic characteristics (reviewed in Rohwer 1994). Most notably, Townsend's have a black crown and face patch, whereas black-throated green warblers have an olive green crown and lighter face. Also, Townsend's have bright yellow on their breast, which extends down to their underparts, whereas black-throated green warblers either have completely white breasts or, more commonly, a pale yellow wash. Morphologically the two overlap in many characters, although Townsend's generally have a longer wing-chord and tail length (Ridgway 1902, Pyle 1997). The two usually have songs that are easily distinguished, with Townsend's exhibiting considerable individual and population differences and black-throated greens having quite stereotyped songs across their range (Wright et al. 1998, Morse and Poole 2005). Finally, in allopatry black-throated green warblers nest in territories composed of mixed-wood, primarily deciduous forests, with some coniferous component usually present (Morse and

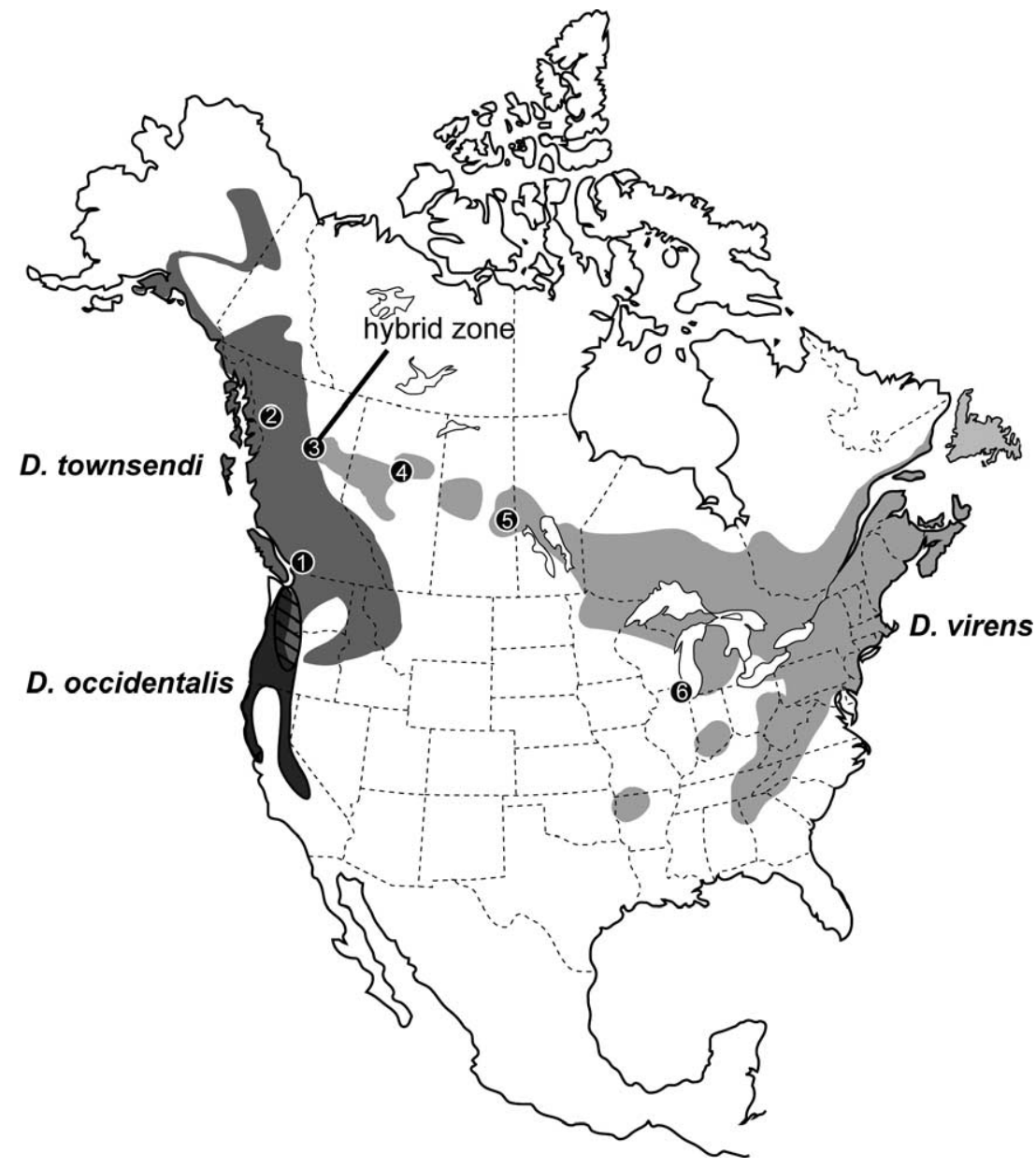

Figure 1. Breeding distributions of Townsend's Dendroica townsendi, black-throated green D. virens and hermit D. occidentalis warblers in North America (adapted from Pearson 1997, Wright et al. 1998 and Morse and Poole 2005), along with the locations of sampling sites (Supplementary material Appendix 1 for site number information). Hatched lines denote the hybrid zone between Townsend's warblers and Hermit warblers in Oregon and Washington. All individuals $(\mathrm{n}=171)$ were males captured on their breeding territories except those $(\mathrm{n}=16)$ obtained from the Field Museum in Chicago, IL, likely on migration. 1, Vancouver and Squamish, BC (VA); 2, Todagin, BC (TO); 3, Chetwynd, BC (hybrid zone, HZ); 4, Lesser Slave Lake (LSL); 5, Hudson Bay, SK (HB); 6, Chicago, IL (CH). 
Poole 2005), whereas Townsend's warblers generally nest in primarily coniferous stands, dominated by spruce and fir (Wright et al. 1998).

In a survey of Townsend's and hermit warblers, Rohwer (1994) reported finding one phenotypic Townsend's warbler with a black-throated green mtDNA haplotype, near Valemount, BC. Given this individual's proximity to the Rocky Mountains and the breeding range of blackthroated green warblers, it was suggested that this was likely a late generation backcross hybrid between the species. At the time, however, the ranges of Townsend's and blackthroated green warblers were not known to come into contact (Rohwer 1994).

In fact, black-throated green warblers are thought to be a recent addition to BC's avifauna (Campbell et al. 2001). An individual collected near Moberly Lake (north of Chetwynd) in 1965 is the first record of a blackthroated green warbler in the province (Salt 1966). Since then, however, the species has become quite common along the eastern slopes of the Rockies, especially near the towns of Chetwynd and Dawson Creek. Some recent observations from breeding bird surveys suggest that some phenotypic black-throated green warblers are now breeding west of the Rocky Mountains, near Prince George, within the range of Townsend's warblers (J. Bradley pers. comm.).

Given these observations of potential range contact and one possible hybrid, we explored northeastern BC with the goal of determining whether Townsend's and black-throated green warblers come into contact and, if so, whether there is a hybrid zone between them. We measured phenotypic and morphological differences between the species to determine how to identify intermediate, hybrid individuals. We also assayed variation in three molecular markers, including mtDNA and two nuclear DNA markers, one on a sex chromosome and one on an autosome; these markers have been used to map another Dendroica hybrid zone in the area (between Audubon's and myrtle warblers; Brelsford and Irwin 2009).

\section{Materials and methods}

\section{Field research}

During the springs of 2007-2010 we captured Townsend's and black-throated green warblers for temporary study from allopatric populations $(n=33)$ and from within the putative contact zone $(\mathrm{n}=138)$. Especially large samples were collected in 2009 by DPLT $(n=114)$ and in 2007 by DEI $(n=49)$. We focused efforts along forestry roads west of the town of Chetwynd, BC where both species were thought to occur (Fig. 2; M. Phinney pers. comm.). For each individual we took standard measurements, photographs, and a small blood sample, then applied bands and released the bird. We supplemented our black-throated green genetic sampling far from the contact zone by including tissue samples from Chicago, IL $(n=16$; provided by the Field Museum) of individuals likely on migration (i.e. most were collected following building collisions); these likely were from breeding locations far east of the contact zone. We aged and sexed all individuals according to Pyle (1997). All of the individuals captured for temporary study were males. Of the 16 museum specimens included 10 were male, 5 were female and 1 was of unknown sex.

\section{Phenotypic and morphometric analyses}

Rohwer (1994) reported a number of consistent plumage differences between Townsend's and black-throated green warblers and how they were manifested in a single hybrid. Here we present an analysis of three of these characteristics, which we found to be the most consistent to score between the species (Fig. 3). Crown colour was scored on a scale from 0 to 4 with ' 0 ' being a completely green crown (corresponding to black-throated green), ' 1 ' having thick black bases to crown feathers, '2' having equal amounts of green and black, ' 3 ' having more black than green and ' 4 ' being completely black (corresponding to Townsend's). As some second-year (SY) Townsend's have a slight olive

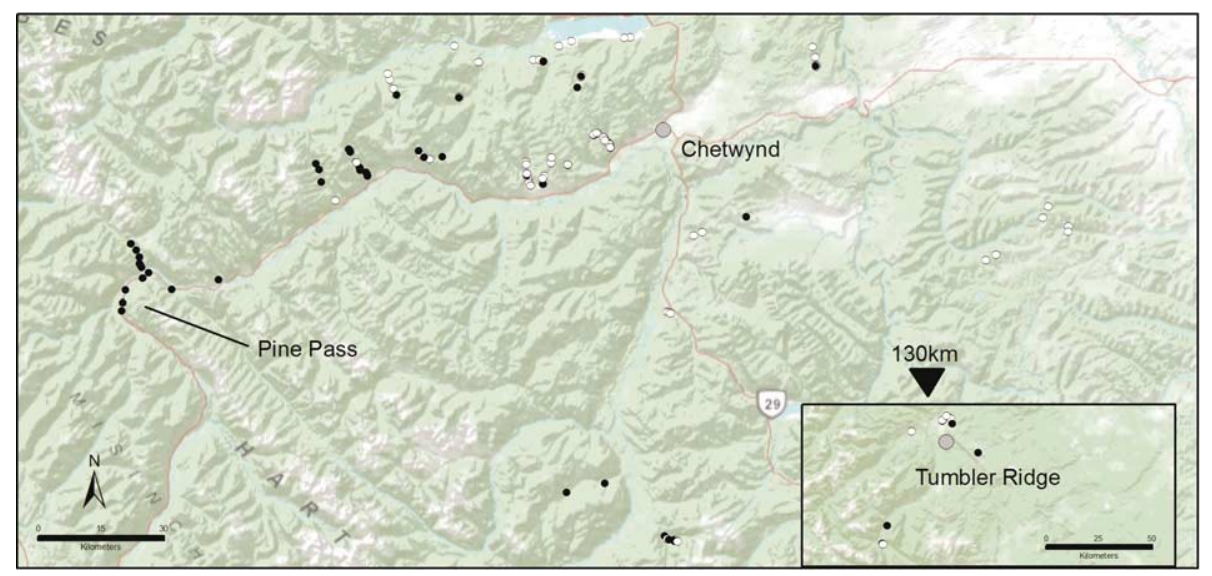

Figure 2. Distribution of mitochondrial DNA haplotypes in the putative hybrid zone. Townsend's mitochondrial types are indicated by filled circles; black-throated green with open circles. Inset includes sampling further south close to the town of Tumbler Ridge, $130 \mathrm{~km}$ south of Chetwynd. Highway 97 (running southwest across the map) crosses Pine Pass in the Rocky mountains at an elevation of approximately $930 \mathrm{~m}$ (this is defined as the crest of the Rockies). 

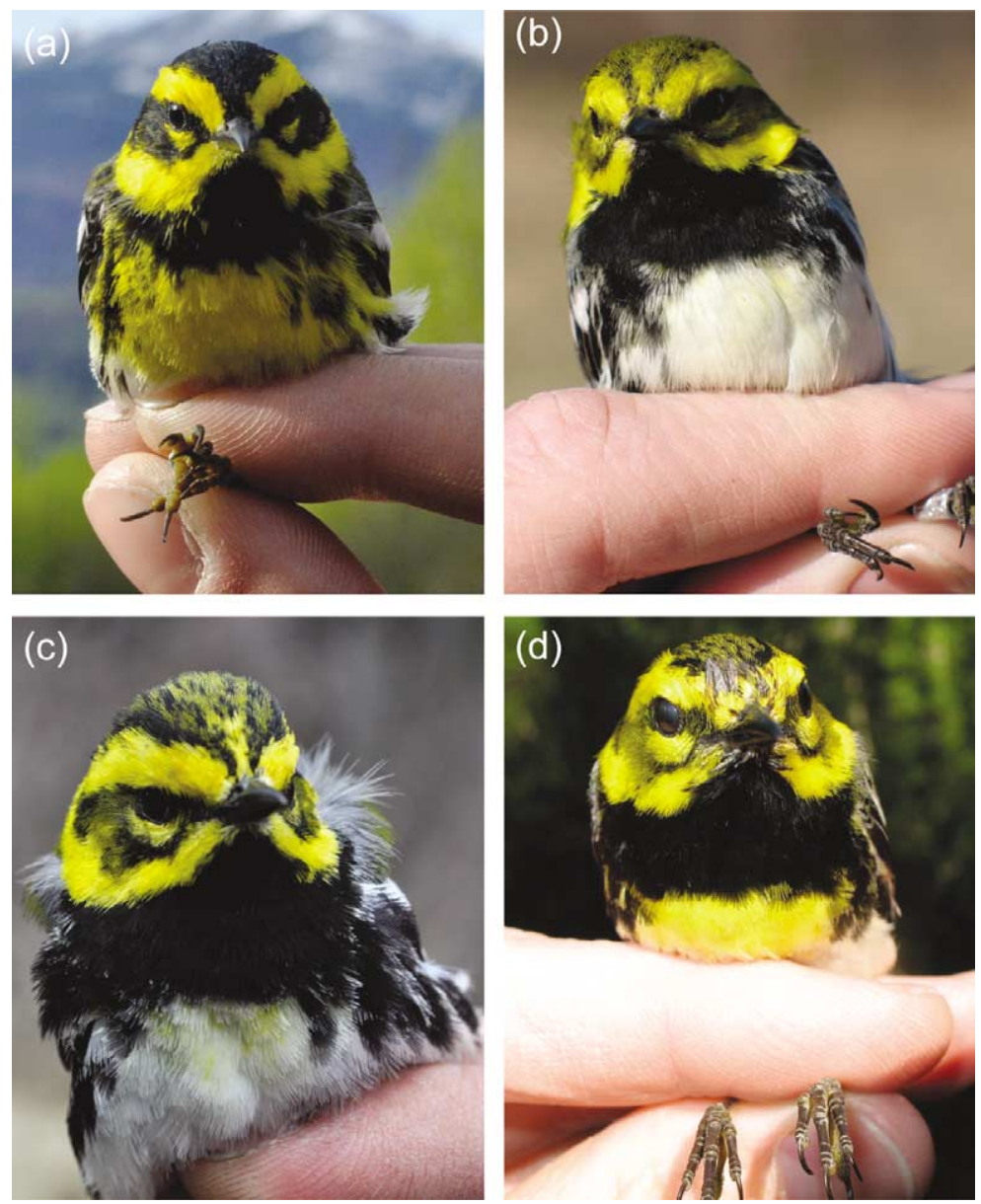

Figure 3. Four male Townsend's/black-throated green warblers from the contact zone chosen to illustrate plumage variation and the mismatch between plumage traits and molecular markers in this area. Plumage was quantified on a scale from 0 to 4 for crown colour, 0 to 2 for face colour and 0 to 3 for breast colour with lower numbers representing trait classes found in black-throated green warblers and higher numbers representing trait classes found in Townsend's warblers: (a) a phenotypic Townsend's ( $4 / 4$ crown, 2/2 face, 3/3 breast) with a black-throated green mtDNA and, (b) a phenotypic black-throated green $(0 / 4$ crown, $0 / 2$ face, $0 / 3$ breast) with a Townsend's mtDNA, (c) a mixed individual (2/4 crown, $1 / 2$ face, $0 / 3$ breast) with a Townsend's mtDNA, and (d) a mixed individual (1/4 crown, $1 / 2$ face, $2 / 3$ breast) with a black-throated green mtDNA. Individuals shown have identification numbers (a) IE31T01, (b) GE12D01, (c) IE24T07, and (d) HF20D02 as found in Supplementary material Appendix 1.

edging to their crown, which eventually becomes black in after-second-year (ASY) birds, we were conservative in our scoring of potential hybrids and scored these SY individuals as 'completely black'. We scored breast colour on a scale from 0 to 3 with ' 0 ' being completely white or faint yellow wash, ' 1 ' having concentrated yellow extending approximately $1 \mathrm{~cm}$ from the throat, '2' having bright yellow extending $3 / 4$ of the way down the breast and ' 3 ' having bright yellow extending throughout the breast. Finally, we scored the face patch on a scale from 0 to 2 with ' 0 ' being faint green or black, ' 1 ' being intermediate, with some dark black and faint green feathers, and ' 2 ' being completely dark black. Again, as some SY Townsend's have a slight lighter edging to their feathers, which eventually becomes black in ASY birds, so we also scored these as 'completely black' as in the crown. We divided each of the scores by the total number of possible classes for that plumage trait and then, by dividing each by the highest possible score, combined each additively to create a 'hybrid index' that ranged between 0 and 1 , with black-throated green warblers being ' 0 ' and Townsend's being ' 1 '.
We also measured six morphological characteristics (according to Pyle 1997): wing-chord (unflattened), tail, tarsus, beak length, beak depth, and beak width. We logtransformed these six morphological variables and identified the major axis of covariation using a principal components analysis (PCA) as implemented in R (R Development Core Team 2006). We fitted cubic splines to each of the morphological traits and the plumage score in $\mathrm{R}$ using a generalized additive model with the 'identity' error link function to determine the best smoothing parameter. To test for differences in the untransformed means of each of these traits we used a Welch's two-sample t-test in R. For this and other analyses we defined the 'hybrid zone' as those populations occurring within $130 \mathrm{~km}$ of the crest of the Rocky mountains.

\section{Molecular analyses}

Blood samples were taken from the brachial vein and stored in Queen's Lysis Buffer (Seutin et al. 1991) and left at ambient temperature until returned to the laboratory. DNA 
was extracted using a phenol-chloroform protocol and resuspended with $50-200 \mu \mathrm{l}$ of TE $(10 \mathrm{~mm}$ Tris- $\mathrm{HCl}$, $1 \mathrm{~mm}$ EDTA, pH 8.0) depending on the size of the pellet and stored at $4^{\circ} \mathrm{C}$. Our choice of molecular markers for distinguishing the taxa was based on limited sequence information from previous surveys (Lovette et al. 1999, Brelsford and Irwin 2009) and the requirement that there was an appreciable frequency difference between allopatric samples.

mtDNA: Lovette et al. (1999) described in detail mitochondrial sequence variation that distinguishes Townsend's and black-throated green mtDNA haplotypes in a $613 \mathrm{bp}$ region of cytochrome oxidase I (COI). We amplified this region of the mitochondrial genome using the primer pair COIa-3' and COIf-5' (Kessing et al. 1989, Lovette et al. 1999). We used a restriction fragment length polymorphism (RFLP) assay to genotype a SNP at $209 \mathrm{bp}$, where there is a G-A polymorphism, with $\mathrm{G}$ common in Townsend's warblers and A common in black-throated green warblers; the restriction enzyme SmaI cuts only the G variant. PCR reactions included $1 \times$ PCR buffer (Invitrogen), $1.5 \mathrm{mM} \mathrm{MgCl}_{2}$ (Invitrogen), $0.2 \mathrm{mM} \mathrm{dNTP}$ mix (New England Biolabs), $0.5 \mu \mathrm{M}$ forward and reverse primer, 0.04 units $\mu 1^{-1}$ Taq DNA polymerase (New England Biolabs), and $2.5 \mathrm{ng} \mu \mathrm{l}^{-1}$ genomic template DNA, in a total volume of $10 \mu \mathrm{l}$. The thermal cycling profile was $3 \mathrm{~min}$ at $94^{\circ} \mathrm{C}$ followed by 35 cycles of $30 \mathrm{~s}$ at $94^{\circ} \mathrm{C}, 30 \mathrm{~s}$ at $54^{\circ} \mathrm{C}$, and $30 \mathrm{~s}$ at $72^{\circ} \mathrm{C}$, ending with $5 \mathrm{~min}$ at $72^{\circ} \mathrm{C}$. We digested $2 \mu \mathrm{l}$ of the PCR product with 2 units of the restriction enzyme SmaI in its appropriate buffer (New England Biolabs), in a total volume of $6 \mu$ l. Products were digested for $2 \mathrm{~h}$ at $37^{\circ} \mathrm{C}$, and digested DNA was visualized by electrophoresis on $2 \%$ agarose gel stained with SYBRSafe (Invitrogen). This digestion cuts the Townsend's PCR product into two fragments (209 and 404 bp) and does not cut the black-throated green product (one $613 \mathrm{bp}$ fragment). A complicating factor is that this digest also does not cut the hermit warbler product (Lovette et al. 1999); in one case a phenotypic Townsend's warbler sampled along the Pacific Coast that had only a single fragment was assumed to have hermit warbler mtDNA due to hybridization with them in that area. For purposes of the cline analysis between Townsend's and black-throated green warblers, we coded this individual as having a Townsend's mtDNA.

Numt-Dco1: Brelsford and Irwin (2009) and Brelsford et al. (2011) described this 'nuclear sequence of mitochondrial origin', an autosomal nuclear marker that is divergent between Dendroica coronata and $D$. auduboni. We sequenced $1091 \mathrm{bp}$ in this region for one individual (two alleles) from each of our focal species using primers numt_up_2.3 (5'-CCTTCCTCTAATTCCCTACTGTCA) and numt_up_R (5'-CAGAGTGACCCCGAGAAAAG) and identified a G-A SNP at $88 \mathrm{bp}$, with the G variant common in black-throated green warblers; this can be genotyped using the restriction enzyme HpyCH4IV (Genbank accession numbers JF310198-JF310201). The PCR, digestion and visualization protocol are the same as above except the annealing temperature was $53.2^{\circ} \mathrm{C}$. This digestion cuts the black-throated green PCR product into two fragments (912 and $179 \mathrm{bp})$ and cuts the Townsend's product into three $(88,824$ and $179 \mathrm{bp})$. We only used the presence/absence of the 824 and 912 bp fragments for genotyping and these were easily distinguished on agarose in both homozygotes and heterozygotes.

CHD1Z: Brelsford and Irwin (2009) and Irwin et al. (2009) used sequence variation in the CHD1Z gene, a Z-linked nuclear marker that is used in molecular sexing of birds, to assay variation across the Dendroica coronatal D. auduboni and Oporonis tolmieilO. philadelphia hybrid zones. In birds, males are the homogametic sex (ZZ) and therefore have two copies of CHD1Z. We amplified and sequenced a 632 bp fragment in two males from each species (Genbank accession numbers JF310002-JF310009) using primers $2550 \mathrm{~F}$ and $2718 \mathrm{R}$ (Fridolfsson and Ellegren 1999) and found a single T-to-A SNP at $147 \mathrm{bp}$ which creates a cut site in Townsend's PCR product (with the A variant) for the restriction enzyme AseI. The PCR, digestion and visualization protocol are the same as above except the annealing temperature for the PCR was $53^{\circ} \mathrm{C}$. This digestion cuts the Townsend's PCR product into three fragments (147, 184 and $301 \mathrm{bp)}$ and cuts the blackthroated green product into two (184 and $448 \mathrm{bp}$ ). We used only the presence/absence of the $301 \mathrm{bp}$ and $448 \mathrm{bp}$ fragments for genotyping. Our sampling included five females and one individual of unknown sex (from museum samples), all of which were coded as having only one CHD1Z allele.

\section{Linkage disequilibrium (LD)}

We estimated LD between the two nuclear genetic markers and between each of the nuclear markers and mtDNA haplotypes. Assuming a large population size, no selection and no migration into the hybrid zone the expectation of estimates of LD is that, given enough time, there should be no association between these genetic markers, which are found on different chromosomes/genomes. Relaxing any of these assumptions may lead to positive $\mathrm{LD}$, which can provide insights into the dynamics of the hybrid zone (Arnold 1993). We performed these analyses with only those individuals that had genetic data for all three of the genetic markers $(n=99)$ and were sampled within $30 \mathrm{~km}$ of the centre of the hybrid zone (which is approximately 50 $\mathrm{km}$ east of the Rockies; see below).

We estimated the composite digenic gametic linkage disequilibrium between the two nuclear markers using the formula $D_{A B}=P_{A B}-p_{A} p_{B}$, defined as the difference between the frequency of a gamete with upper-case alleles for loci $\mathrm{A}$ and $\mathrm{B}$ and the product of the frequencies of those alleles $\left(\mathrm{p}_{\mathrm{A}} \mathrm{p}_{\mathrm{B}}\right)$ in the population (Weir 1996). In the current case this is the difference between the frequency of CHD1Z and numt-Dcol alleles that are common in Townsend's warblers and are found in individuals in the hybrid zone $\left(\mathrm{P}_{\mathrm{AB}}\right)$ and the product of those alleles in this population $\left(\mathrm{P}_{\mathrm{A}} \mathrm{P}_{\mathrm{B}}\right) ; \mathrm{D}_{\mathrm{AB}}$ is the equivalent to $\mathrm{D}_{\mathrm{ab}}$ calculated based on alleles common in black-throated green warblers. We also calculated the cytonuclear allelic disequilibrium between each mtDNA haplotype and the two nuclear markers. To do this we used the formula $\mathrm{D}=\mathrm{P}_{\mathrm{MA}}-\mathrm{P}_{\mathrm{M}} \mathrm{P}_{\mathrm{A}}$, where disequilibrium is defined the difference between the frequency of a gamete with the mtDNA haplotype and the nuclear allele $\left(\mathrm{P}_{\mathrm{MA}}\right)$ and the product of the frequencies 
of the mtDNA haplotype and nuclear marker $\left(\mathrm{P}_{\mathrm{M}} \mathrm{P}_{\mathrm{A}}\right.$; Asmussen et al. 1987, Arnold 1993). Given that these two nuclear loci are not fixed in black-throated green warblers, the maximum possible LD is likely lower than for markers that are fixed.

\section{Cline analyses}

The transition of allele frequencies and phenotypic traits across many hybrid zones can be modeled effectively by a three-stepped cline, consisting of a central sigmodal curve bracketed by two exponential tails (Barton and Hewitt 1985, Szymura and Barton 1986). We used the program Cfit6 (Gay et al. 2008) to estimate the parameters for the best fitting clines for the three molecular markers. We did not fit clines for the morphometric and plumage traits. For each of the markers we fit the centre, width and height parameters of a scaled logit cline. We did not fit the exponential tails of the stepped function because estimating these parameters requires dense sampling at the edges of the hybrid zone. To determine whether the best fitting model allowed the clines for different markers to have different centres and slopes, suggesting they are subject to different localized patterns of dispersal or selection, or consisted of clines with identical centres and/or slopes, we ran Cfit for each of the four combinations (i.e. unconstrained, centres constrained, slopes constrained and both constrained). To group populations to generate allele frequencies we separated groups based on natural breaks in our sampling, with an average population size of 12 individuals ranging from 3 to 26. We used likelihood-ratio tests (LRT) and calculated Akaike information criteria (AIC; Akaike 1974) to determine the best fitting clines with varying sets of constraints on cline centers and slopes.

\section{Results}

\section{Range contact}

Near the towns of Chetwynd and Tumbler Ridge, BC we found an area where Townsend's and black-throated green warblers occur in sympatry. Our sampling indicates that there are no large gaps in the distribution between the two taxa in this area or further to the west or east. In many cases we captured individuals that were phenotypically Townsend's and phenotypically black-throated green in the same mist net. We also captured a number of individuals in this area that had mixed plumage traits and were not easily classified as either species (Fig. 3).

\section{Morphometrics and plumage}

Although measurements from the six morphometric traits overlap between the two species, the means of some traits (wing, tail, tarsus and beak width) differed significantly between allopatric populations (Table 1). Individuals in the contact zone were on average intermediate between the two parental species for many of the traits. In the PCA, the first beak morphometric traits while PC3 was loaded with wing and second principal components were highly loaded with

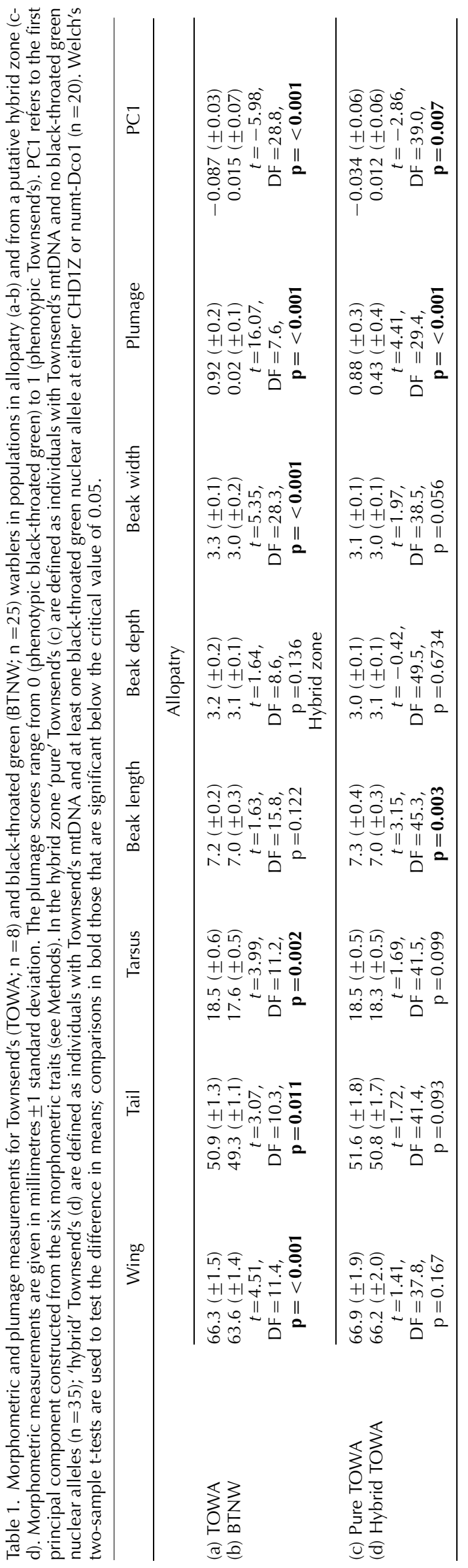


and tail measurements (Table 2). Although sigmoidal clines were not fitted for these traits, the cubic splines showed a clinal transition generally coincident with the molecular traits (Fig. 4).

Plumage score, which quantified variation in breast, crown and face colouration, showed distinct differences between the species and was intermediate and combined in complex ways in many individuals in the hybrid zone. The transition in plumage traits occurs over a narrow region approximately $40 \mathrm{~km}$ east of the crest of the Rocky Mountains (Fig. 4). Most individuals in this area have plumage traits that resemble one or the other parental species; only four of 137 individuals in the overlap area were perfectly intermediate using the plumage score criteria described above. The plumage trait we found most useful in diagnosing the two species and most variable in the contact zone was the colour of the crown, from black in Townsend's warblers to green in black-throated green warblers, and a mixture of both in putative hybrids (Fig. 3).

\section{Molecular markers}

While our allopatric sampling within the range of the Townsend's warbler was limited, previous studies with greater geographic scope found only one instance of blackthroated green mtDNA haplotypes in these populations (Rohwer 1994, Rohwer et al. 2001, Krosby and Rohwer 2009). We found no evidence of mitochondrial introgression of black-throated green haplotypes into the allopatric range of Townsend's warblers. Our sampling in the allopatric range of black-throated greens was more detailed and was supplemented by museum samples. We found only one instance of a mismatch in this allopatric area: one Townsend's mtDNA haplotype was found in a phenotypically pure black-throated green warbler in Lesser Slave Lake, Alberta (approximately $450 \mathrm{~km}$ east of the hybrid zone).

The numt-Dcol marker was fixed in our sample of Townsend's warblers but was polymorphic for an alternate allele in black-throated green warblers both inside and out of the contact zone: in black-throated green populations far from the contact zone in Alberta, Saskatchewan and Illinois, the allele fixed in Townsend's warbler was also found at a frequency of $0.43,0.38$, and 0.28 , respectively (Fig. 5). The SNP in CHD1Z is also fixed in Townsend's warblers and is polymorphic for an alternate allele in black-throated green populations in Alberta but, in contrast to numt-Dco1, is fixed for this alternate allele in Saskatchewan and Illinois. If the Townsend's allele was maintained at the proportion we sampled it in Alberta (0.4), finding no individuals with the

Table 2. Factor loadings and variance explained of the first three principal components produced in the PCA of morphological variables.

\begin{tabular}{lccr}
\hline & PC1 & PC2 & \multicolumn{1}{c}{ PC3 } \\
\hline Wing & -0.1296 & 0.2202 & -0.5306 \\
Tail & -0.1471 & 0.2871 & -0.5591 \\
Tarsus & -0.1411 & 0.2610 & -0.1966 \\
Beak length & -0.5492 & 0.6695 & 0.4286 \\
Beak depth & -0.3090 & -0.2288 & -0.4170 \\
Beak width & -0.7380 & -0.5482 & 0.0978 \\
\% variation & $40.7 \%$ & $19.5 \%$ & $15.7 \%$ \\
\hline
\end{tabular}

Townsend's allele in either of these populations further east is highly unlikely (i.e. 0 out of $36 \mathrm{CHD} 1 \mathrm{Z}$ alleles sampled, $\mathrm{p}<0.0001$; Fig. 5), indicating this Townsend's allele drops dramatically in frequency between central Alberta and eastern Saskatchewan (Table 4).

The estimated linkage disequilibrium (D) between the two nuclear markers in the centre of the zone was 0.05 , suggesting that there is a positive non-random association between these two markers. This was comparable to the LD estimated between mtDNA and each of the markers: for CHD1Z the estimate was 0.06 and for numt-Dco 1 LD was 0.04 .

\section{Hybridization}

Within the contact zone, there were often mismatches between mitochondrial haplotypes and plumage score: out of 68 individuals that we classified as black-throated greenlike (plumage score 0-0.2), 10 had a Townsend's mtDNA, and out of 35 Townsend's-like individuals (plumage score $0.8-1$ ), 4 had black-throated green mtDNA (Fig. 3, 6).

Considering the mtDNA together with the nuclear markers suggests even more extensive hybridization. The nuclear markers we used (CHD1Z and numt-Dco1) are fixed in Townsend's warblers but are polymorphic in blackthroated green warblers (at least in populations within 500 $\mathrm{km}$ of the hybrid zone; see above). Aside from one instance of a Townsend's mtDNA in an allopatric black-throated green warbler, it is only in the contact zone that we find novel combinations of Townsend's mtDNA and blackthroated green nuclear markers (Fig. 7). Of 53 individuals in the putative hybrid zone with Townsend's mitochondria, 20 individuals have one or more black-throated green alleles at CHD1Z or numt-Dco1, suggesting a conservative estimate of $38 \%$ of individuals as likely hybrids or backcrosses (Fig. 7).

To assess whether birds with molecular evidence of hybridization tended to have phenotypes consistent with hybridization, we compared individuals within the hybrid zone that had differing genetic constitutions. As the two nuclear markers are not fixed in black-throated greens (at least near the contact zone) we compared individuals that have only Townsend's mtDNA and no black-throated green nuclear markers ('pure Townsend's'; Table 1c) to individuals that have a Townsend's mtDNA but also have at least one black-throated green nuclear allele from either CHD1Z or numt-Dco1 ('hybrid Townsend's'; Table 1d). For beak length, PC1 and plumage score, individuals with one or more black-throated green nuclear allele were significantly different from those with all Townsend's alleles, each in the expected direction of having more black-throated green-like measurements.

\section{Cline analyses}

Estimating the centre and width of the best fitting clines allows us to test whether selection is acting differently on the genetic markers we assayed: narrow clines indicate selection is stronger compared to wide clines; the noncoincidence of cline centres indicates that the markers may be subject to different localized patterns of selection. The 


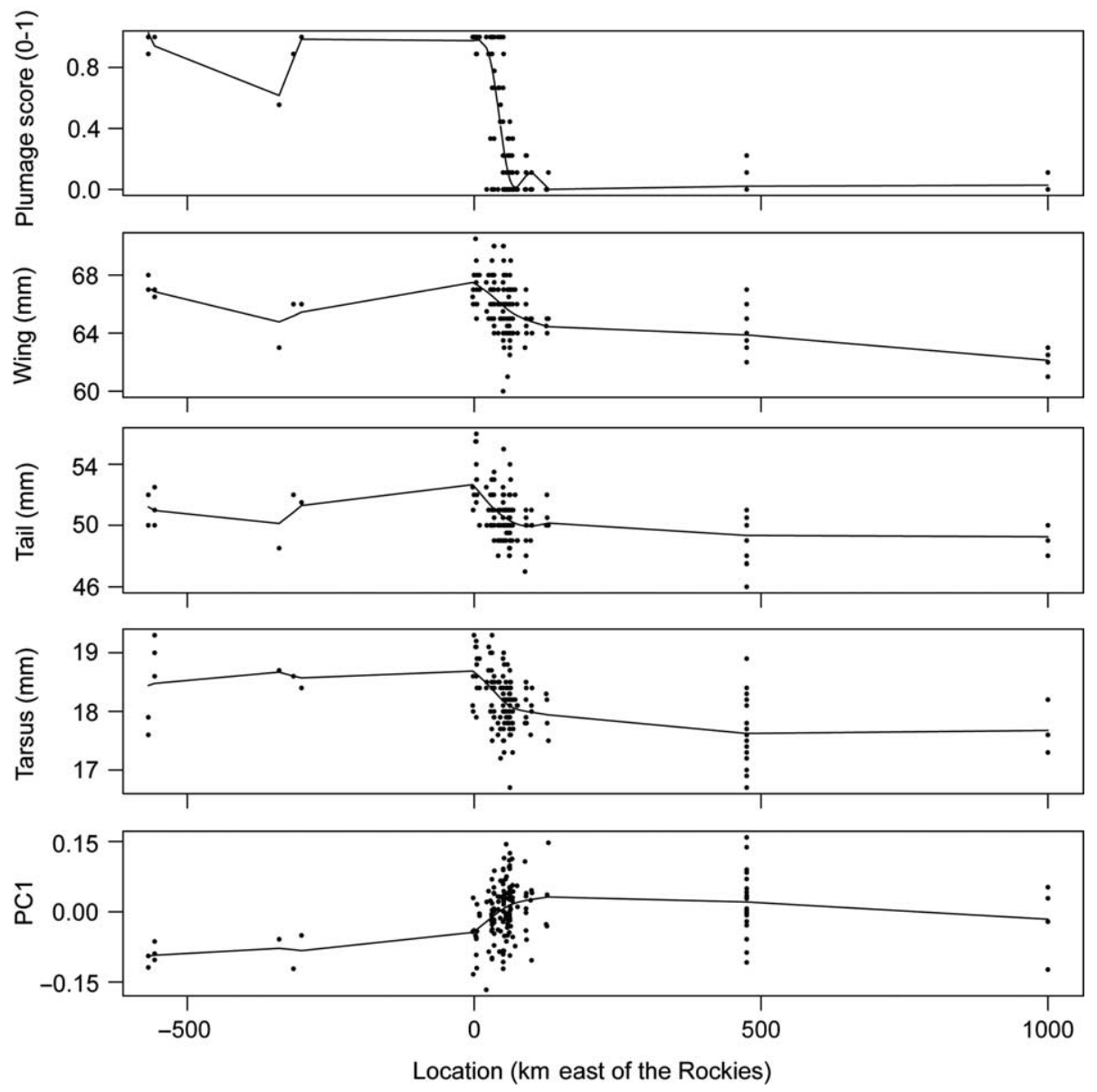

Figure 4. Clines in morphological and plumage traits across a hybrid zone between Townsend's and black-throated green warblers. Points represent individuals and locations are distances $(\mathrm{km})$ east of the crest of the Rocky Mountains. Plumage score ranges from 0 (phenotypic black-throated green) to 1 (phenotypic Townsend's). PC1 has the highest loadings from the three measurements of beak (Table 2). Lines are fitted by cubic splines in $\mathrm{R}$.
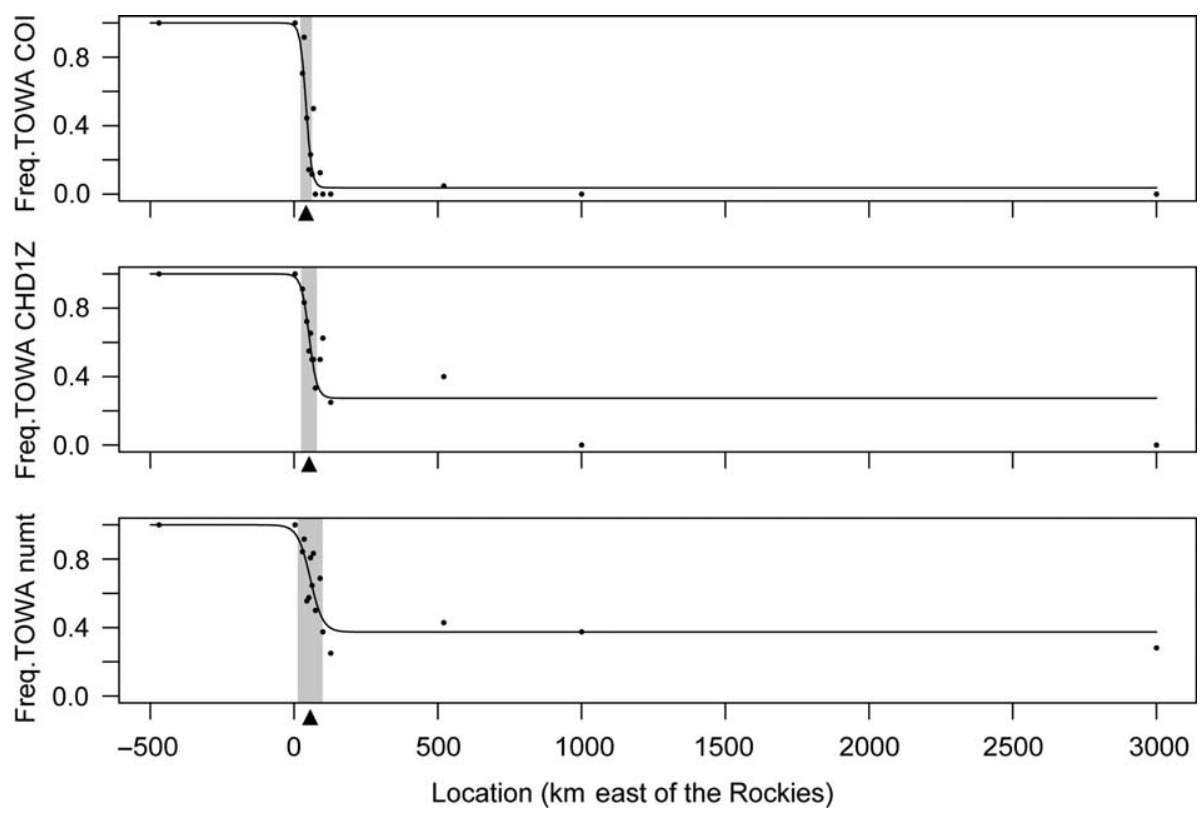

Figure 5. Clines in molecular markers across a hybrid zone between Townsend's and black-throated green wablers. Points are allele freqencies in COI (mitochondrial), CHD1Z (Z-linked) and numt-Dco1 (autosomal) and locations are averaged distances (km) in relation to the crest of the Rocky Mountains. The lines represent the best fitting cline, as estimated by Cfit 6 (Table 3a; Gay et al. 2008), and the arrows and gray boxes show its center and width. 
Table 3. Estimates of cline parameters using the program Cfit 6 (Gay et al. 2008) for three molecular markers across a hybrid zone between Townsend's and black-throated green warblers when (a) the markers each have their own centers and slopes, (b) have their centers constrained, (c) have their slopes constrained and (d) have both their centers and slopes constrained. The number of parameters for each model $(n)$, log-likelihood and the AIC score for each is listed. The best model (i.e. lowest AIC) is highlighted in bold. The estimates of width are given in $\mathrm{km}$ and cline centers are in $\mathrm{km}$ east from the crest of the Rockies.

\begin{tabular}{|c|c|c|c|c|c|c|c|c|}
\hline & \multicolumn{2}{|c|}{ (a) No constraint } & \multicolumn{2}{|c|}{ (b) Center constrained } & \multicolumn{2}{|c|}{ (c) Slope constrained } & \multicolumn{2}{|c|}{ (d) Centers and slopes constrained } \\
\hline & Width & Center & Width & Center & Width & Center & Width & Center \\
\hline $\mathrm{COI}$ & 40 & 41 & 40 & 46 & 53 & 41 & 48 & 46 \\
\hline CHD1Z & 54 & 52 & 46 & 46 & 53 & 52 & 48 & 46 \\
\hline numt-Dco1 & 87 & 56 & 70 & 46 & 53 & 49 & 48 & 46 \\
\hline $\mathrm{n}$ & & 9 & & 7 & & 7 & & 5 \\
\hline Log-likelihood & & -449.67 & & -453.35 & & -452.01 & & -454.62 \\
\hline AIC & & 917.2 & & 920.7 & & 918.02 & & 919.24 \\
\hline
\end{tabular}

model in which each of the three markers has its own centre and slope (Table 3a) had two additional parameters as compared to models in which each of the markers had the same centre (Table 3b) or slope (Table 3c) and had four additional parameters as compared to the model where each marker had the same centre and slope (Table 3d). Using likelihood-ratio tests and AIC (Table 3) we found a model where both cline centers and slopes were unconstrained for the three molecular markers was the best fit to the data (loglikelihood $=-449.67 ; \quad$ AIC $=917.22) \quad$ compared to a model where the centers were constrained (log-likelihood $=-453.35 ; \quad$ AIC $=920.7$; likelihood ratio test: $\left.\chi^{2}=7.36, \mathrm{DF}=2, \mathrm{p}=0.02\right)$ and a model where both centres and slopes were constrained (log-likelihood $=-$ 454.62; $\mathrm{AIC}=919.24 ;$ likelihood ratio test: $\chi^{2}=9.9$, $\mathrm{DF}=4, \mathrm{p}=0.04)$ although the LRT suggests this is not a better fit when just the slopes were constrained (loglikelihood $=-452.01 ; \quad$ AIC $=918.02 ; \quad$ likelihood ratio test: $\left.\chi^{2}=4.68, \mathrm{DF}=2, \mathrm{p}=0.1\right)$. The model where each cline has its own centre and slope does not provide a better fit to the data when both model selection statistics (AIC and LRT) are controlled for sample size (using $\mathrm{AIC}_{c}$; results not shown) and multiple comparisons (LRT Bonferroni-correction $\alpha=0.05 / 3$; results not shown). Therefore, while the best model is where the clines are considered statistically non-coincident, these differences have low support and variation among markers is relatively small: the cline centres for the molecular markers range from $41 \mathrm{~km}$ (COI) to 56 $\mathrm{km}$ (numt-Dco1) east of the Rocky Mountains (Table 3; Fig. 5), and cline widths range from $40 \mathrm{~km}$ for COI to 87 $\mathrm{km}$ for numt-Dco1 (Table 3; Fig. 5).

\section{Discussion}

Our results show for the first time that Townsend's and black-throated green warblers hybridize extensively in the Peace Region of northeastern British Columbia, home to hybrid zones within a number of other pairs of divergent avian taxa. Many of the individuals in this area have plumage traits that resemble one or the other parental species, which is likely why this hybrid zone was not described previously. However, our combined analysis of morphometric, plumage and genetic variation shows that many individuals in this area have a mixture of traits of the two species, a pattern that can only be explained by hybridization in the contact zone.

Clines in various traits are located on the eastern slope of the Rocky Mountains (average cline center for the three markers is $50 \mathrm{~km}$ east of the crest), and occur over a very narrow distance (the average width from the three markers is $60 \mathrm{~km}$ ) in comparison to the estimated single-generation root mean squared dispersal distance $(30 \mathrm{~km}$ as estimated in

Table 4. Frequencies of molecular markers in allopatry (sites 1, 2, 4-6; Fig. 1) and at a series of locations across a hybrid zone between Townsend's and black-throated green warblers (site 3). Frequencies are relative to the TOWA allele in COI (mitochondrial), CHD1Z (Z-linked) and numt-Dco1 (autosomal). Phenotypic and morphometric measurements are averages for each site and locations are averaged distances $(\mathrm{km})$ in relation to the crest of the Rocky Mountains. See caption for Figure 1 for site names and locations.

\begin{tabular}{|c|c|c|c|c|c|}
\hline Site name (distance from crest) & Phenotype & Morpho PC1 & Freq. COI & Freq. numt-Dco1 & Freq. CHD1Z \\
\hline $1-$ VA $(-560 \mathrm{~km})$ & 0.98 & -0.094 & 1 & 1 & 1 \\
\hline $2-\mathrm{TO}(-320 \mathrm{~km})$ & 0.81 & -0.077 & 1 & 1 & 1 \\
\hline $3-\mathrm{HZ}(3 \mathrm{~km})$ & 0.99 & -0.047 & 1 & 1 & 1 \\
\hline $3-\mathrm{HZ}(29$ km) & 0.80 & -0.023 & 0.71 & 0.84 & 0.91 \\
\hline $3-\mathrm{HZ}(35 \mathrm{~km})$ & 0.80 & 0.005 & 0.92 & 0.92 & 0.83 \\
\hline $3-\mathrm{HZ}(44$ km) & 0.63 & -0.002 & 0.44 & 0.56 & 0.72 \\
\hline $3-\mathrm{HZ}(51 \mathrm{~km})$ & 0.20 & 0.003 & 0.14 & 0.58 & 0.55 \\
\hline $3-\mathrm{HZ}(57$ km) & 0.05 & 0.012 & 0.23 & 0.81 & 0.65 \\
\hline $3-\mathrm{HZ}(62 \mathrm{~km})$ & 0.10 & 0.027 & 0.12 & 0.65 & 0.50 \\
\hline $3-H Z$ (67 km) & 0.13 & 0.035 & 0.50 & 0.83 & 0.50 \\
\hline $3-\mathrm{HZ}(74$ km) & 0.04 & -0.002 & 0.00 & 0.50 & 0.33 \\
\hline $3-\mathrm{HZ}(90$ km) & 0.11 & 0.015 & 0.13 & 0.69 & 0.50 \\
\hline $3-\mathrm{HZ}(100$ km) & 0.03 & 0.002 & 0.00 & 0.38 & 0.63 \\
\hline $3-\mathrm{HZ}$ (127 km) & 0.03 & 0.032 & 0.00 & 0.25 & 0.25 \\
\hline 4 - LSL (521 km) & 0.02 & 0.021 & 0.05 & 0.43 & 0.40 \\
\hline $5-\mathrm{HB}(\sim 1000 \mathrm{~km})$ & 0.03 & -0.016 & 0.00 & 0.38 & 0.00 \\
\hline $6-\mathrm{CH}(\sim 3000 \mathrm{~km})$ & $* *$ & $* *$ & 0.00 & 0.28 & 0.00 \\
\hline
\end{tabular}


(a) Individuals in hybrid zone with Townsend's mtDNA

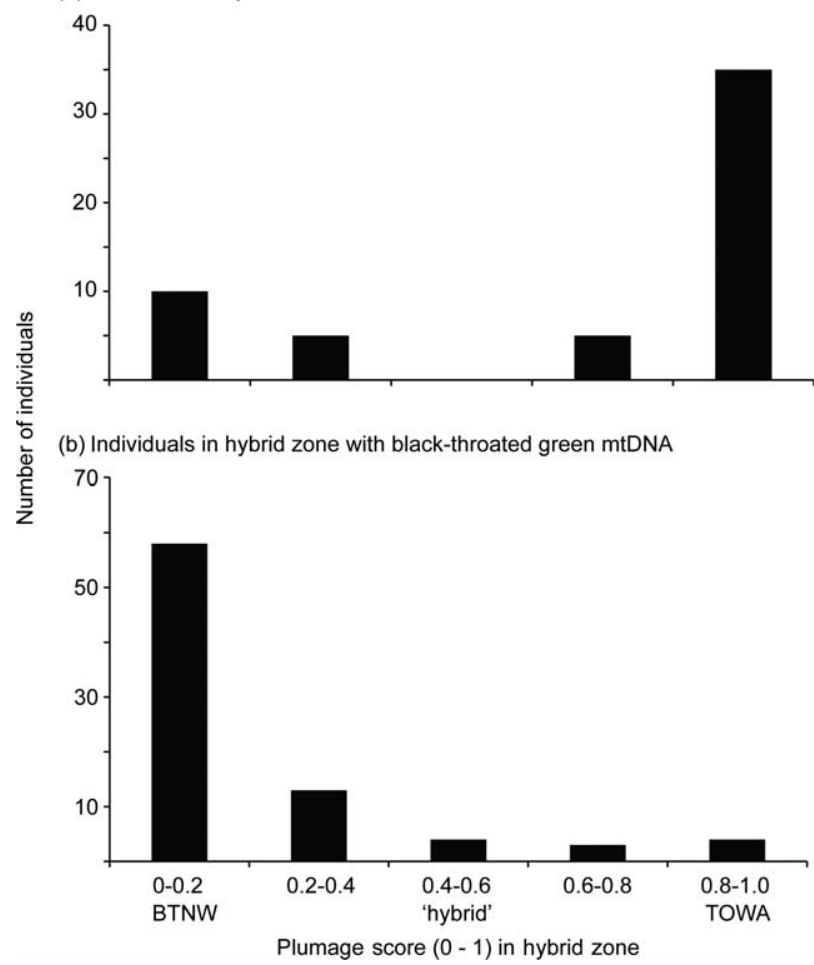

Figure 6. Relationship between plumage score, with 0 being phenotypic black-throated green and 1 being phenotypic Townsend's, and mitochondrial type within the contact zone.

hermit and Townsend's warblers; Rohwer et al. 2001). Using this assumed dispersal distance and a conservative estimate of the time of range contact (i.e. 1965, Salt 1966) a neutral model of diffusion upon secondary contact ( $w=\sqrt{2 \pi \sigma^{2} t}$, where $w$ is cline width, $\sigma$ is RMS dispersal distance, and $t$ is the number of generations since initial contact) would predict a cline with a width of approximately $360 \mathrm{~km}$ after 23 generations (assuming a generation time of two years), much wider than observed (Barton and Hewitt 1985, Barton and Gale 1993). This suggests that some form of pre-mating reproductive isolation or postmating selection against hybrids is keeping the zone narrow

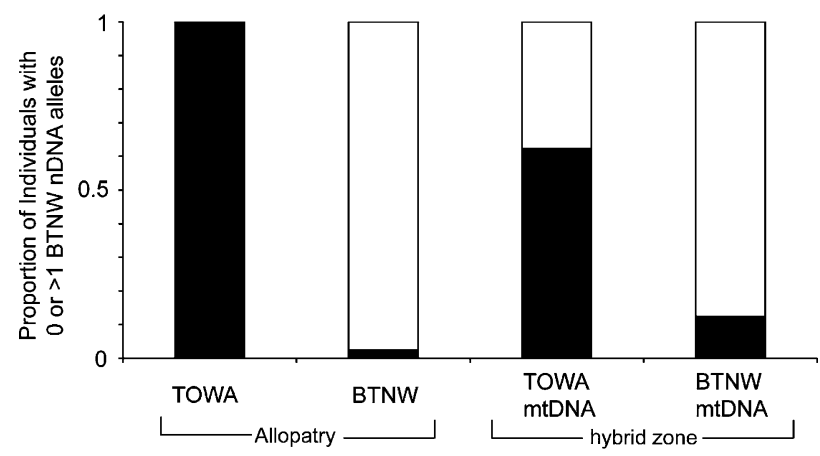

Figure 7. Proportion of individuals in Townsend's (TOWA; $n=$ 8) or black-throated green (BTNW; $n=40)$ allopatric populations and in the hybrid zone with either no black-throated green nuclear alleles (filled) or at least one black-throated green allele at either CHD1Z or numt-Dco1 (clear). Individuals in the hybrid zone are distinguished by either having a Townsend's $(n=53)$ or blackthroated green $(\mathrm{n}=81) \mathrm{mtDNA}$.
(Price 2008). The positive values of linkage disequlibrium between each of the genetic markers also support the conclusion that selection may be maintaining the zone; however positive values of $\mathrm{LD}$ are also consistent with recent secondary contact.

One potential factor that could be maintaining reproductive isolation in the hybrid zone is pre- or post-mating selection on song, which is an important trait in most songbirds for both male-male territory defence and solicitation of females (Catchpole and Slater 1995). Townsend's and black-throated green warblers have easily distinguished songs. Like other Dendroica warblers (Wright et al. 1998, Morse and Poole 2005) each species has two stereotyped song classes. Our informal observations in the hybrid zone suggest that song types from both species occur in the contact zone, although this is not always predictive of an individual's phenotype. We also have observed individuals switching between song types, indicating that some individuals can sing songs of both species. The ability to learn heterospecific song types has been proposed in other avian hybrid zones as a means to defend territories from either species (Price 2008). In a recent analysis of song variation in the MacGillivray's/mourning warbler hybrid zone, which occurs in the same area, song is also not strongly predictive of phenotype or genotype (Kenyon et al. 2011). In that case there is evidence that the differences observed in allopatry are not maintained in the contact zone and that heterospecific song learning may be contributing to hybridization (Kenyon et al. 2011). A thorough analysis of song variation across the Townsend's and black-throated green hybrid zone is warranted.

Another behavioural factor that could be important in this hybrid zone is difference in male-male aggression. Studies of the hermit/Townsend's warbler hybrid zone found that Townsend's warblers are much more aggressive than hermit warblers, possibly explaining the hybrid zone movement from Townsend's into the range of hermit warblers (Pearson 2000, Pearson and Rohwer 2000). We observed many cases of territorial aggression between phenotypic Townsend's and black-throated green individuals, and informal playback experiments suggest that both species are territorially defensive to each other - both respond to recordings of either species. Study of song playback experiments in this hybrid zone is recommended to determine whether there are differences in recognition and aggression between the two taxa and their hybrids.

That the center of this hybrid zone is coincident with the transition between the mixed-wood boreal forest east of the Rockies and the conifer-dominated cordilleran forests to the west suggests that habitat isolation between the parental species or selection against hybrids with intermediate or inferior habitat preferences might have a role in maintaining the zone. This ecological transition is more likely to be an important factor in this hybrid zone (as compared to the hybrid zones between Audubon's/myrtle and MacGillivray's/ mourning warblers; Brelsford and Irwin 2009, Irwin et al. 2009) because evidence from outside the hybrid zone shows a preference of the parental species for these different forest types (Pearson 1997, Wright et al. 1998 and Morse and Poole 2005). Preston et al. (2007) recently combined black-throated green occurrence and remote sensing data to model habitat suitability of this species in 
northeastern BC. Interestingly, suitability shows a decline coincident with the centres of the clines we studied here. This observation is consistent with the hypotheses that 1) exogenous factors are maintaining the zone or 2) that this area represents a density trough, which are thought to attract endogenously controlled tension zones (Barton and Hewitt 1985). That the two species do come into contact often, however, suggests that pre-mating isolation based on habitat differences alone is unlikely. A more detailed ecological characterization and niche modeling approach in this and other avian hybrid zones is needed to investigate the importance of this ecological transition in maintaining this suture zone (Swenson 2006, Thomassen et al. 2010).

Another selective factor that may be important in maintaining this narrow zone is seasonal migratory behaviour. Migration is under strong genetic influence in most migratory songbirds (Helbig 1996, Irwin and Irwin 2005, Pulido 2007). Townsend's and black-throated green warblers differ strongly in their migratory routes and wintering ranges (Wright et al. 1998, Morse and Poole 2005), raising the possibility that hybrids might have a suboptimal mixture of migratory traits. If the hybrid zone represents a 'migratory divide', with Townsend's orienting southsouthwest in the autumn and black-throated green warblers orienting south-southeast, selection may be acting against hybrid individuals with intermediate and potentially inferior migratory orientation, as has been suggested in the case of willow warblers in central Sweden (Bensch et al. 2009) and a number of other cases (Irwin and Irwin 2005, Irwin 2009, Rohwer and Irwin 2011). Research on the migratory behaviour of birds in and near the hybrid zone would help reveal whether this is a strong source of selection against hybrids.

In the approximately one million years separating these two species from a common ancestor (Lovette et al. 2010), genetic incompatibilities may have accrued between them. Because theoretical analyses have suggested an important role for the Z-chromosome in avian speciation and hybrid incompatibilities, we expected to see a more narrow cline in the Z-linked marker, CHD1Z, as compared to the other molecular markers, as some other studies of avian hybrid zones have found (Carling and Brumfield 2009, Qvarnström and Bailey 2009, Backström et al. 2010). In our case, the CHD1Z cline had an intermediate width compared to the clines of the two other markers, not providing support for this hypothesis, although examination of more molecular markers is needed to evaluate it fully.

The pattern of variation in CHD1Z in the populations of black-throated green warblers we sampled was surprising: in Alberta there is a polymorphism of the Townsend's and black-throated green alleles, whereas further east the blackthroated green allele was fixed (Fig. 5). We suggest three possible explanations for this pattern: 1) that the hybrid zone has moved to the west, 2) that a separate mutation that disrupts the restriction digest has become fixed or is at high frequency in the populations east of Alberta, and 3) that there has been introgression through hybridization from Townsend's warblers at the CHD1Z gene. Given the distance and our survey of other molecular markers we suggest that hybrid zone movement is unlikely. We suggest that introgression from Townsend's warblers is a more parsimonious explanation than fixation of a third allele over a large fraction of the black-throated green range. Whether this is consistent with a neutral process or the result of positive selection deserves further study. Given this potential introgression and the conservation concern of blackthroated green warblers in BC (Cooper et al. 1997) we recommend a detailed spatio-temporal sampling of this hybrid zone and allopatric populations to test for evidence of potential zone movement or more extensive genomic introgression than reported here.

In conclusion, we have provided the first description of a hybrid zone between Townsend's and black-throated green warblers. The narrowness of this hybrid zone and the similar clines in three molecular markers and a variety of phenotypic traits suggest that the hybrid zone is likely maintained by some form of selection, characteristic of many tension zones observed between other avian taxa (Price 2008). Given this, we suggest the two should continue to be treated as separate taxonomic species. A combination of factors likely maintains the zone: ecological differences and habitat preferences may govern the location, but intrinsic or behavioural incompatibilities likely produce selection against hybrids, maintaining the zone's narrow width. Further behavioural, ecological and genomic characterization of this and other contact zones located in this small area of northeastern BC is needed to reveal the selective forces maintaining the distinctiveness of these forms despite hybridization.

Acknowledgements - We thank Mark Phinney for advice, assistance and keeping a keen eye on the warblers in the Peace. We thank Ilya Povalyaev for providing field assistance and the Field Museum in Chicago, Illinois for providing genetic samples. Financial support was provided by the Natural Sciences and Engineering Research Council of Canada (Discovery Grants 311931-2005 and 3119312010 to DEI; CGS-D to DPLT) and the National Science Foundation of the USA (graduate research fellowship to $A B$ ). Molecular analysis was conducted in the UBC Laboratory for Molecular Biogeography, funded in part by grants to DEI from the Canadian Foundation for Innovation and the British Columbia Knowledge Development Fund. For providing permits we thank the UBC Animal Care Committee and Environment Canada (Master Banding Permit 10746, Scientific Permit 59-050344 for work in British Columbia, and Scientific Permit CWS05-A003 for work in Alberta). We thank Staffan Bensch for providing useful comments on the manuscript.

\section{References}

Akaike, H. 1974. A new look at the statistical model identification. - IEEE Trans. Autom. Contr. 19: 716-723.

Anderson, T. M., vonHoldt, B. M., Candille, S. I., Musiani, M., Greco, C., Stahler, D. R., Smith, D. W., Padhukasahasram, B., Randi, E., Leonard, J. A., Bustamante, C. D., Ostrander, E. A., Tang, H., Wayne, R. K. and Barsh, G. S. 2009. Molecular and evolutionary history of melanism in North American gray wolves. - Science 323: 1339-1343.

Arnold, J. 1993. Cytonuclear disequilibria in hybrid zones. - Annu. Rev. Ecol. Syst. 24: 521-554.

Asmussen, M., Arnold, J. and Avise, J. C. 1987. Definition and properties of disequilibrium statistics for associations between nuclear and cytoplasmic genotypes. - Genetics 115: 755-768. 
Backström, N., Lindell, J., Zhang, Y., Palkopoulou, E., Qvarnström, A., Saetre, P.-S. and Ellegren, H. 2010. A high-density scan of the $\mathrm{Z}$ chromosome in Ficedula flycatchers reveals candidate loci for diversifying selection. - Evolution, in press.

Barrowclough, G. F. 1980. Genetic and phenotypic differentiation in a wood warbler (genus Dendroica) hybrid zone. - Auk 97: 655-668.

Barton, N. and Hewitt, G. 1985. Analysis of hybrid zones. - Annu. Rev. Ecol. Syst. 16: 113-148.

Barton, N. H. and Gale, K. S. 1993. Genetic analysis of hybrid zones. - In: Harrison, R. G. (ed.), Hybrid zones and the evolutionary process. Oxford Univ. Press, pp. 13-45.

Bensch, S., Gran, M., Müller, N., Gay, L. and Åkesson, S. 2009. Genetic, morphological, and feather isotope variation of migratory willow warblers show gradual divergence in a ring. - Mol. Ecol. 18: 3087-3096.

Brelsford, A. and Irwin, D. E. 2009. Incipient speciation despite little assortative mating: the yellow-rumped warbler hybrid zone. - Evolution 63: 3050-3060.

Brelsford, A., Milá, B. and Irwin, D. E. 2011. Hybrid origin of Audubon's warbler. - Mol. Ecol., in press.

Campbell, R. W., Dawe, N. K., McTaggart-Cowan, I., Cooper, J. M., Kaiser, G. W., Stewart, A. C. and McNall, M. C. E. 2001. The birds of British Columbia. Vol. 4. Passerines. - Univ. of British. Columbia Press.

Carling, M. and Brumfield, R. 2009. Speciation in Passerina buntings: introgression patterns of sex-linked loci identify a candidate gene region for reproductive isolation. - Mol. Ecol. 18: 834-847.

Catchpole, C. K. and Slater, P. K. B. 1995. Bird song: biological themes and variations. - Cambridge Univ. Press.

Cooper, J. M., Enns, K. A. and Shepard, M. G. 1997. Status of the black-throated green warbler in British Columbia. - BC Ministry of Environment Wildlife Working Report WR-80.

Fridolfsson, A. K. and Ellegren, H. 1999. A simple and universal method for molecular sexing of non-ratite birds. - J. Avian Biol. 30: 116-121.

Gay, L., Crochet, P.-A., Bell, D. and Lenormand, T. 2008. Comparing clines on molecular and phenotypic traits in a hybrid zones: a window on tension zone models. - Evolution 62: 2789-2806.

Grant, P. R. and Grant, B. R. 1992. Hybridization of bird species. - Science 256: 193-197.

Helbig, A. J. 1996. Genetic basis, mode of inheritance and evolutionary changes of migratory directions in Palearctic warblers (Aves: Sylvidae). - J. Exp. Biol. 199: 49-55.

Hubbard, J. P. 1969. The relationships and evolution of the Dendroica coronata complex. - Auk 86: 393-432.

Irwin, D. E. 2009. Speciation: new migratory direction provides route toward divergence. - Curr. Biol. 19: R1111-R1113.

Irwin, D. E. and Irwin, J. H. 2005. Siberian migratory divides: the role of seasonal migration in speciation. - In: Greenberg, R. and Marra, P. P. (eds), Birds of two worlds: the ecology and evolution of migration. Johns Hopkins Univ. Press, pp. 27 40.

Irwin, D. E., Brelsford, A., Toews, D. P. L., MacDonald, C. and Phinney, M. 2009. Extensive hybridization in a contact zone between MacGillivray's warblers Oporornis tolmiei and mourning warblers $O$. philadelphia detected using molecular and morphological analyses. - J. Avian Biol. 40: 539-552.

Kenyon, H. L., Toews, D. P. L. and Irwin, D. E. 2011. Can song discriminate between MacGillivray's and mourning warblers in a narrow hybrid zone? - Condor, in press.

Kessing, B., Croom, H., Martin, A., McIntosh, C., McMillan, W. O. and Palumbi, S. P. 1989. The simple fool's guide to PCR, version 1.0. - Spec. Publ. Dept Zool., Univ. of Hawaii, Honolulu.
Krosby, M. and Rohwer, S. 2009. A 2000 km genetic wake yields evidence for northern glacial refugia and hybrid zone movement in a pair of songbirds. - Proc. R. Soc. B 276: 615-621.

Lovette, I., Bermingham, E., Rohwer, S. and Wood, C. 1999. Mitochondrial restriction fragment length polymorphism (RFLP) and sequence variation among closely related avian species and the genetic characterization of hybrid Dendroica warblers. - Mol. Ecol. 8: 1431-1441.

Lovette, I., Pérez-Emán, J., Sullivan, J., Banks, R., Fiorentino, I., Córdoba-Córdoba, S., Echeverry-Galvis, M., Barker, F. K., Burns, K. J., Klicka, J., Lanyon, S. M. and Bermingham, E. 2010. A comprehensive multilocus phylogeny for the woodwarblers and a revised classification of the Parulidae (Aves). - Mol. Phylogenet. Evol., in press.

Mayr, E. and Short, L. L. 1970. Species taxa of North American birds, a contribution to comparative systematics. - Publ. Nuttall Ornithol. Club 9: 1-127.

Morse, D. H. and Poole, A. F. 2005. Black-throated green warbler (Dendroica virens). - In: Poole, E. (ed.), The birds of north america online. Cornell Laboratory of Ornithol., Ithaca, $<$ http://bna.birds.cornell.edu/bna/species/055/>.

Payseur, B. 2010. Using differential introgression in hybrid zones to identify genomic regions involved in speciation. - Mol. Ecol. Res. 10: 806-82.

Pearson, S. F. 2000. Behavioral asymmetries in a moving hybrid zone. - Behav. Ecol. 11: 84-92.

Pearson, S. F. 1997. Hermit warbler (Dendroica occidentalis). - In: Poole, E. (ed.), The birds of North America online. Cornell Laboratory of Ornithol., Ithaca, <http://bna.birds.cornell.edu/bna/species/303/>.

Pearson, S. F. and Rohwer, S. 2000. Asymmetries in male aggression across an avian hybrid zone.- Behav. Ecol. 11: 93-101.

Preston, M. I., Bunnel, F. L. and Vernier, P. 2007. Identification of habitat variables and information gaps for providing scaledependent management recommendations to monitor blackthroated green warbler and Connecticut warbler in northeast British Columbia. - Report prepared for BC Ministry of Environment and Louisiana-Pacific Canada.

Price, T. 2008. Speciation in birds. - Roberts and Co. Publishers, Greenwood Village, Co.

Pulido, F. 2007. The genetics and genetics of migration in insects. - BioScience 57: 165-174.

Pyle, P. 1997. Identification guide to North American birds. Part 1. Columbidae to Ploceidae. - Slate Creek Press, Bolinas, CA.

Qvarnström, A. and Bailey, R. I. 2009. Speciation through evolution of sex-linked genes. - Heredity 102: 4-15.

Rabosky, D. and Lovette, I. 2008. Explosive evolutionary radiations: decreasing speciation or increasing extinction through time? - Evolution 62: 1866-1875.

Remington, C. L. 1968. Suture-zones of hybrid interaction between recently joined biotas. - In: Dobzhansky, T., Hecht, M. K. and Steere, W. C. (eds), Evolutionary biology. Plenum Press, pp. 321-428.

Ridgway, R. 1902. The birds of North and Middle America: a descriptive catalogue of the higher groups, genera, species, and subspecies known to occur in North America. - US Natl Mus. Bull. 50: 562-565.

Rohwer, S. 1994. Two new hybrid Dendroica warblers and new methodology for inferring parental species. - Auk 111: 441449.

Rohwer, S. and Wood, C. 1998. Three hybrid zones between Hermit and Townsend's warblers in Washington and Oregon. - Auk 115: 284-310.

Rohwer, S. and Irwin, D. E. 2011. Molt, orientation, and avian speciation. - Auk 128: 419-425. 
Rohwer, S., Bermingham, E. and Wood, C. 2001. Plumage and mitochondrial DNA haplotype variation across a moving hybrid zone. - Evolution 55: 405-422.

Salt, W. R. 1966. Some unusual bird records from the Peace River district. - Can. Field-Nat. 80: 114-115.

Seehausen, O. 2006. Conservation: losing biodiversity by reverse speciation. - Curr. Biol. 16: R334-R337.

Seutin, G., White, B. N. and Boag, P. T. 1991. Preservation of avian blood and tissue samples for DNA analyses. - Can. J. Zool. 69: 82-90.

Short, L. 1972. Hybridization, taxonomy and avian evolution. - Ann. Miss. Bot. Gard. 59: 447-453.

Swenson, N. G. and Howard, D. 2005. Clustering of contact zones, hybrid zones, and phylogeographic breaks in North America. - Am. Nat. 166: 581-591.

Swenson, N. G. 2006. GIS-based niche models reveal unifying climatic mechanisms that maintain the location of avian hybrid zones in a North American suture zone. - J. Evol. Biol. 19: 717-725.

Szymura, J. and Barton, N. 1986. Genetic analysis of a hybrid zone between the fire-bellied toads, Bombina bombina and B. variegata, near Cracow in southern Poland. - Evolution 40: 1141-1159.

Supplementary material (Appendix J5360 at <www.oikos office.lu.se/appendix $>$ ). Appendix 1.

Online access to all photographs used for plumage score analysis: <http://dx.doi.org/10.5061/dryad.j407q >
Thomassen, H., Cheviron, Z., Freedman, A., Harrigan, R., Wayne, R. and Smith, T. 2010. Invited review: spatial modelling and landscape-level approaches for visualizing intra-specific variation. - Mol. Ecol. 19: 3532-3548.

Toews, D. and Irwin, D. E. 2008. Cryptic speciation in a Holarctic passerine revealed by genetic and bioacoustic analyses. - Mol. Ecol. 17: 2691-2705.

Vallender, R., Robertson, R., Friesen, V. and Lovette, I. 2007. Complex hybridization dynamics between golden-winged and blue-winged warblers (Vermivora chrysoptera and Vermivora pinus) revealed by AFLP, microsatellite, intron and mtDNA markers. - Mol. Ecol. 16: 2017-2029.

Vallender, R., Gagnon, J.-P. and Lovette, I. 2009. An intergeneric wood-warbler hybrid (Mniotilta varia $\times$ Dendroica coronata) and use of multilocus DNA analyses to diagnose avian hybrid origins. - Wilson J. Ornithol. 121: 298-305.

Weir, B. S. 1996. Genetic data analysis II. - Sinauer.

Weir, J. and Schluter, D. 2004. Ice sheets promote speciation in boreal birds. - Proc. R. Soc. B 271: 1881-1887.

Wright, A. L., Hayward, G. D., Matsuoka, S. M. and Hayward, P. H. 1998. Townsend's warbler (Dendroica townsendi). - In: Poole, A. (ed.), The birds of North America online, Cornell Lab of Ornithology, Ithaca, <http://bna.birds.cornell.edu/ $\mathrm{bna} / \mathrm{species} / 333 />$. 